\title{
$\nabla$
}

\section{Physiological and lifestyle factors contributing to risk and severity of peri-orbital dark circles in the Brazilian population*}

\author{
Mary S Matsui ${ }^{1}$ \\ Garrett Vanderover ${ }^{1}$ \\ Christopher $\mathrm{J}^{1}$ \\ Juliana Regina Bueno ${ }^{2}$ \\ Mário Sérgio Bombarda Júnior ${ }^{2}$
}

Sérgio Schalka

Christina G. Fthenakis ${ }^{1}$

Patricia Camarano Pinto Bombarda ${ }^{2}$

Bianca Lenci Inácio Viscomi²

DOI: http://dx.doi.org/10.1590/abd1806-4841.20153520

\begin{abstract}
BACKGROUND: Peri-orbital dark circles are a cosmetic concern worldwide, and have been attributed to hyperpigmentation from allergy or atopic dermatitis, blood stasis, structural shadowing effects, and a thin epidermis/dermis under the eye. It is of interest to better understand lifestyle and demographic risk factors and the relative impact of melanin, blood and epidermal/dermal factors on the severity of Peri-orbital dark circles.

Oвjective: To compare by non-invasive imaging the impact of biological factors to a visual grading scale for Peri-orbital dark circles, and test the correlation of various demographic factors with Peri-orbital dark circles. Methods: Subjects completed a lifestyle and health survey, and Peri-orbital dark circles severity was evaluated using standardized photographs. Hyperspectral image analysis was used to assess the contributions of melanin, blood volume, degree of blood oxygen saturation, and dermal scattering.

RESULTS: Family history was the most significant risk factor for Peri-orbital dark circles. The average age of onset was 24 years, and earlier onset correlated with higher severity scores. Asthma was significantly associated with Peri-orbital dark circles scores, but self-reported allergy was not. In this study, sleep was not correlated with Peri-orbital dark circles scores. Hyperspectral imaging indicated that melanin was the dominant correlate for Peri-orbital dark circles severity, while oxygen saturation was secondary. The difference between under-eye and cheek measurements for $\Delta \mathrm{L}^{*}$ and $\Delta \mathrm{E}^{*}$ were the most significant instrumental parameters correlated with visual assessment of Peri-orbital dark circles severity.

ConCLusion: Although typically associated with lack of sleep, risk of Peri-orbital dark circles is primarily hereditary. The main factors contributing to the appearance of Peri-orbital dark circles are melanin and (deoxygenated) blood.
\end{abstract}

Keywords: Facial Dermatoses; Skin care; Skin pigmentation

\section{INIRODUCTION}

The presence of under-eye dark circles (DUEC) is a common cosmetic complaint worldwide, and various cosmetic, surgical and laser treatments are employed to ameliorate this condition. It is often referred to as peri-orbital hypermelanosis, reflecting the prominent role that hyperpigmentation plays in the etiology of DUEC. Other factors that have been identified as possible causes of DUEC include: blood stasis or dilation of the superficial microvasculature, shadowing due to periorbital structural geometry, and thin translucent skin overlying the orbicularis oculi muscle. ${ }^{1,2}$ It has been suggested that DUEC worsens with aging, due to skin sagging and altered subcutaneous fat distribution. ${ }^{3,4}$

It is important to identify the underlying contributors to DUEC. Some clinicians have argued that because various factors cause infraorbital dark circles, the cause must be identified before appropriate 
treatment can be initiated. In a study of Japanese subjects, an analysis of biopsies suggested that there was increased melanin and melanophages in the upper dermis when DUEC was present. ${ }^{5}$

The impact of lifestyle factors on the incidence and severity of DUEC has been discussed and examined at length, but some misconceptions may still remain. For example, it is often said that lack of sleep and fatigue provoke the appearance of DUEC or worsening of existing DUEC. ${ }^{1,2}$ However, this is difficult to reconcile with the physiological measurements that suggest melanin is the predominant factor in DUEC, since melanin typically has a longer time frame for development and resolution. In contrast, others have argued that dehydration may make the underlying melanin and deoxygenated blood more visible.

This study had two objectives: first, to assess by non-invasive hyperspectral imaging the relative impact of melanin, blood oxygenation and dermal scattering to a visual comparative severity grading scale for DUEC; and second, to test the correlation of various etiological and demographic factors with DUEC.

\section{METHODS}

\section{Subjects}

The study was conducted at the Medcin Clinic, Osasco, Sao Paulo, Brazil, with 495 female subjects aged 13-71 years. It was conducted in compliance with the Code of Federal Regulations, Title 21, Section 50 (21CFR50), the Good Clinical Practices standards (GCP-ICH and Document of Americas), the international standards for research involving human beings (Declaration of Helsinki) and National Health Council Resolution 196, dated October 10, 1996, as amended.

\section{Rank assessment of dark circles}

Each subject's DUEC severity was ranked by medical personnel using as samples an array of photographs (5 samples per rank) which had been separated into five DUEC categories: $1=$ absent, 2 $=$ mild, $3=$ mild $/$ moderate, $4=$ moderate, and $5=$ severe. Visual assessment is an important criterion for patient relevance in the context of cosmetic treatment, as instrumental measurements can be significantly different without clinical improvement. The patient and test raters simultaneously process both color intensity and skin surface area covered by the DUEC.

For these reasons, hyperspectral imaging instrumental measurements were tested for correlation with DUEC severity visual assessments.

\section{Survey of etiological factors.}

Information was collected from subjects via a questionnaire. Demographic data were collected by the investigators, including hair and eye color, ethnic self-identification, sun exposure history, sleep quality / quantity, history of smoking, alcohol use, allergies and family history of DUEC. In addition, responses were gathered to questions about acne, age at which subject was first aware that she had DUEC, frequency of product use for DUEC or eye area, frequency of sunscreen use, and subjects' list of factors that they believe contributed to DUEC.

\section{Spectral analysis.}

Hyperspectral image analysis was used to determine the relative contributions of melanin volume, blood volume, degree of blood oxygen saturation in the superficial skin layers, and dermal scattering. A noncontact, non-invasive spectral imaging tool was used, providing diffused light transport theory to model and quantify blood, melanin, dermal scattering and skin oxygen saturation. ${ }^{6}$ A spectral camera (Themis Vision VNIR400H) acquired reflectance images with 640x640 pixels and 10-bit data acquisition, over a field of view of $25 \mathrm{~cm} \times 25 \mathrm{~cm}$, at a distance of $2 \mathrm{~m}$ from subjects' faces. Tungsten-halogen bulbs (Total lamps, by Lowel Pro) provided light from 600nm to $925 \mathrm{~nm}$. Light was passed through glass polarizers (Schneider Optics) placed 7 inches in front of the lamp. A bank of light-emitting diodes (LEDs, by Litepanel) was placed just above the camera, centered on the optical axis, penetrating thin film polarizers, to augment the illumination. Black and white calibration tiles were placed on either side of the face, with reflectances of Rw.std $=0.989$ and Rb.std $=0.013$, respectively. The volume fraction amounts of melanin $(\mathrm{M})$, the average volume fraction of whole blood $(150 \mathrm{~g} \mathrm{Hb} /$ liter) (B), the oxygen saturation of the blood (S) and the dermal scattering coefficient (D), were evaluated for each subject under the eye and on the uninvolved cheek for each side of the face.

In addition, spectrophotometric measurements were taken of representative areas under the eye, on the cheek, and on the upper forem arm with a Xrite Spectrolino spectrophotometer, capturing the percentage reflectance of the skin color and then calculating the color using the CIE L*a*b* color system. Using the spectrophotometer, the $L^{*}$ parameter expresses color brightness (varying between a value of 100 for a white surface and 0 for a black surface). The a* parameter represents changes along a red-green axis where positive values indicate a red surface and negative values indicate a green surface. Positive $b^{*}$ values indicate a yellow surface while negative values indicate a blue surface. Further, skin values $a^{*}$ and $b^{*}$ typically have a range of 5-30 depending on the technology used to measure color. 


\section{Statistical analysis.}

For factors with 2 levels ("yes" or "no" for example), association with DUEC was assessed using the Wilcoxon rank sum test (also known as the Mann-Whitney test). For factors with more than 2 levels, such as age, association with DUEC and differences between categories were assessed using the Kruskal-Wallis test. If the factor was described by an ordinal scale (e.g. sleep quality), Kendall's tau was used to correlate with DUEC, in addition to Kruskal Wallis. If the Kruskal-Wallis test or the Kendall's tau test were significant, with $\mathrm{P}<0.05$ (revealing an association between DUEC and the factor), then the Wilcoxon rank sum test was used to compare the DUEC across all pairs of factor levels. Hyperspectral imaging data were analyzed using linear regression, while the overall statistical package used for analysis was the $\mathrm{R}$ programming language and software for statistical computing and graphics. Comparisons were considered significant if $\mathrm{P} \leq 0.05$.

\section{RESULTS}

A total of 495 subjects were evaluated. The age of the subjects ranged from 13 to 71 with a median age of 36 and a mean age of 37 . Table 1 summarizes the distribution of DUEC severity in the study population, according to both DUEC severity in the entire group and age distribution. The median DUEC in all age groups was 3 , though higher age groups tended to have higher proportions of DUEC level $5(p=0.015)$. The number of subjects in each group is indicated, along with the percentage of total subjects in that category. From 495 subjects enrolled in the study, 12 subject's data were excluded

The distribution of Fitzpatrick skin types of all subjects is shown in figure 1. There was no significant relationship between skin type and DUEC $(p=0.55)$, although it should be noted that there were comparatively few cases of types I and VI. There was no relationship between DUEC scores and hair or eye color (data not shown).

Table 2 shows the age at which subjects reported first noticing they had DUEC. In agreement with other studies, the age of onset was relatively young, with an average age of 24 , while most reported the condition

\section{Fitzpatrick Skin Type of Subjects}

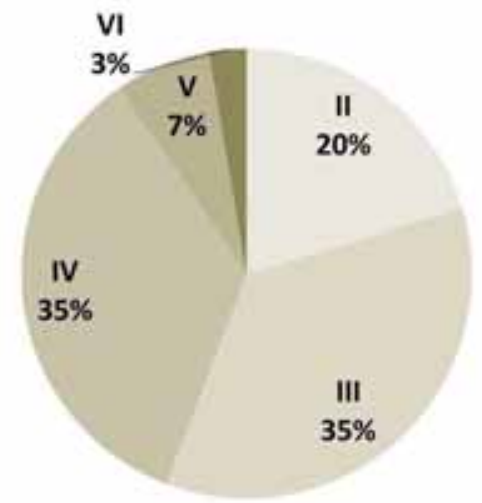

Figure 1: Distribution of Fitzpatrick skin types of all subjects

TABLE 1: Distribution of DUEC severity - general and according to the age group

\begin{tabular}{lllllll}
\hline & Total & $\begin{array}{l}\text { DUEC }=\mathbf{1} \\
\mathbf{n}(\%)\end{array}$ & $\begin{array}{l}\text { DUEC }=\mathbf{2} \\
\mathbf{n}(\%)\end{array}$ & $\begin{array}{l}\text { DUEC }=\mathbf{3} \\
\mathbf{n}(\%)\end{array}$ & $\begin{array}{l}\text { DUEC=4 } \\
\mathbf{n}(\%)\end{array}$ & $\begin{array}{l}\text { DUEC = 5 } \\
\mathbf{n}(\%)\end{array}$ \\
\hline Total & 483 & $22(4,6)$ & $154(31,9)$ & $107(22,2)$ & $125(25,9)$ & $75(15,6)$ \\
Age Group & & & & & \\
$10-19$ & 22 & $0(0)$ & $10(45)$ & $7(32)$ & $4(18)$ & $1(5)$ \\
$20-29$ & 115 & $8(7)$ & $39(34)$ & $27(23)$ & $27(23)$ & $14(12)$ \\
$30-39$ & 150 & $7(5)$ & $52(35)$ & $28(19)$ & $40(27)$ & $23(15)$ \\
$40-49$ & 117 & $1(1)$ & $35(30)$ & $26(22)$ & $35(30)$ & $20(17)$ \\
$50+$ & 75 & $6(8)$ & $17(23)$ & $18(24)$ & $18(24)$ & $16(21)$ \\
\hline
\end{tabular}

DUEC 1 = absent; 2 = mild $; 3=$ mild $/$ moderate 4 = moderate $; 5=$ severe 
between the ages of 20-50. Earlier onsets were associated with higher DUEC values. In particular, patients with onset ages of 10-19 had significantly higher DUEC values than those with onset ages of 30$39(p=0.023)$ and 40-49 $(p=0.038)$. Further, those with onset ages of 20-29 had significantly higher DUEC scores than individuals with onset ages of 30-39 $(\mathrm{p}=0.032)$.

Family history was investigated to determine whether DUEC "runs in the family". Most subjects $(71.9 \%)$ reported a family history of DUEC, while $28.1 \%$ did not. Among all subjects, the correlation between family history of DUEC and presence of DUEC was significant $(p=0.018)$. The most frequent ties indicated were female relatives, mothers and grandmothers.

There was a significant relationship between self-reported asthma (both subjects themselves and separately, a relative with asthma) and DUEC (Table 3). However, there was no relationship between hay fever and DUEC, or eczema and DUEC, as shown in table 3 . In addition, neither acne nor alcohol use bore any relation to DUEC.

Interestingly, there was no association between sleep behavior and DUEC, as assessed by the eight questions displayed in Table 4. Treating sleep issues separately, then not a single question correlates with DUEC severity. Equally, taking all questions together, there is no correlation with sleep behavior.
The associations between hyperspectral imaging measurements and expert ranking of DUEC severity are displayed in figure $2 \mathrm{a}-\mathrm{d}$. Spectral imaging values are shown in relative units on the y-axes. Dermatologists' DUEC severity scores appear on the $x$-axes. As DUEC severity increases, melanin values increase under the eye but do not change in the uninvolved cheek, resulting in a correlation between $\triangle \mathrm{M}$ and DUEC severity of $\mathrm{p}<0.001$, meaning that the difference in melanin content between the cheek and undereye areas contributes significantly to the visible perception of DUEC.

Oxygen saturation also appears to play a key role in the visibility of DUEC, as: a) oxygen saturation of blood under the eye decreases as DUEC severity increases, and $b$ ) the difference in saturation levels between the cheek and eye $(\Delta S)$ and DUEC severity are also highly significantly correlated. This relationship between oxygen saturation and DUEC severity indicates that the blood under the eye is less saturated, possibly due to stasis.

Upon spectrophotometry, the $\mathrm{L}^{*}$ value (lightness) under the eye was inversely related to the perceived severity of DUEC, and since the $L^{*}$ value of the cheek did not vary with changing DUEC, the contrast in lightness $\left(\Delta \mathrm{L}^{*}\right.$ : the difference in $\mathrm{L}^{*}$ between the DUEC and the uninvolved cheek) was significantly related to perceived DUEC scores at $p<0.001$.

TABLE 2: Age of onset and DUEC severity

\begin{tabular}{|c|c|c|c|c|c|c|c|c|}
\hline \multirow[t]{2}{*}{ Query } & \multicolumn{2}{|c|}{ Subject response } & \multirow{2}{*}{$\begin{array}{l}\mathrm{N}(\%) \\
1\end{array}$} & \multicolumn{2}{|c|}{ DUEC severity } & \multirow[b]{2}{*}{4} & \multirow[b]{2}{*}{5} & \multirow[t]{2}{*}{ P value } \\
\hline & & & & 2 & 3 & & & \\
\hline \multirow{9}{*}{$\begin{array}{l}\text { Age of onset among "yes" } \\
\text { in self-assessment; } \\
\text { Age < } 10 \text { excluded }\end{array}$} & $10-19$ & 109 & 4 & 24 & 25 & 27 & 29 & \multirow{9}{*}{$0.020^{* *}$} \\
\hline & & & $3.7 \%$ & $22 \%$ & $22.9 \%$ & $24.8 \%$ & $26.6 \%$ & \\
\hline & $20-29$ & 94 & $\begin{array}{l}1 \\
1.1 \%\end{array}$ & $\begin{array}{l}29 \\
30.9 \%\end{array}$ & $\begin{array}{l}18 \\
19.1 \%\end{array}$ & $\begin{array}{l}29 \\
30.9 \%\end{array}$ & $\begin{array}{l}17 \\
18.1 \%\end{array}$ & \\
\hline & $30-39$ & 77 & 0 & 32 & 19 & 20 & 5 & \\
\hline & & & $0 \%$ & $41.6 \%$ & $24.7 \%$ & $26 \%$ & $6.5 \%$ & \\
\hline & $40-49$ & 30 & 2 & 11 & 7 & 6 & 4 & \\
\hline & & & $6.7 \%$ & $36.7 \%$ & $23.3 \%$ & $20 \%$ & $13.3 \%$ & \\
\hline & $50+$ & 3 & 0 & 1 & 0 & 1 & 0 & \\
\hline & & & $0 \%$ & $50 \%$ & $0 \%$ & $50 \%$ & 0 & \\
\hline
\end{tabular}


The difference in the red value $\left(\Delta \mathrm{a}^{*}\right)$ between DUEC and the cheek also significantly increased with DUEC severity $(p=0.008)$, indicating a localized, red component in the visual assessment of DUEC. This is congruent with the observation that increased blood volume (assessed by hyperspectral image analysis) was associated with increased DUEC scores. The yellow-blue values $\left(b^{*}\right)$ were not correlated with DUEC severity, and neither was the dermal scattering component of the hyperspectral image analysis.

\section{DISAUSSION}

The most common factors cited for the occurrence of DUEC are melanin deposition, especially in the dermis, vasculature stasis and shadowing due to structural characteristics.

Several methods have been employed to evaluate the contribution of erythema, dermal composition/thickness and pigment to DUEC. It has been reported that non-contact type instrumentation is best for measuring reflectance from the curved and easily deformable lower eye area. ${ }^{7}$ Both spectrophotometric and non-contact hyperspectral image analysis data obtained from this study of almost 500 women, aged 13-71, indicated that the largest physiological contributor to DUEC is melanin, and that melanin was the dominant correlate for DUEC severity, blood volume and oxygen saturation were secondarialy related. This is consistent with other published observations that used a variety of measurement techniques. Vershoore et al, for example, used a SIAscopy technique in 33 Indian subjects and concluded that the total melanin and dermal melanin content was higher in dark circles than in normal skin. ${ }^{8}$ Watanabe et al. examined the periorbital biopsies of 12 Japanese subjects and concluded that the visible color was due to dermal melanosis. ${ }^{9}$ The authors of another study in which biopsy specimens were collected from 28 subjects who had had DUEC for an average of 26 years concluded that an increase in melanin content was the primary difference between the eye area and a control area. ${ }^{10}$

It has been suggested that increased melanin in the undereye area results from the presence of melanin inside dermal macrophages and pigmentary incontinence. Unfortunately, current, non-invasive, spectral techniques used do not enable differentiation between epidermal and dermal melanin. Nonetheless, the overwhelming contribution of melanin to DUEC severity, whether in the epidermis, dermis or melanophages, would suggest that acute variations (e.g. overnight, $24-48$ hours) in perceived severity occur due to dehydration or increased inflammation but would be minor in relation to the contribution of melanin. Graziosi et al. discussed this and also concluded that short-term changes in DUEC are unlikely to be caused by changes in melanin content. 10 They suggested that under such circumstances, changes in vascular dilation or dehydration may play a larger role in DUEC.

Further, it has been argued that there are ethnic differences in contributing factors to DUEC. For example, several authors have stated that Asians, in particular, tend to have DUEC resulting from postinflammatory hyperpigmentation and are primarily vascular in etiology. ${ }^{11}$ They used this observation to explain why skin lightening creams are often inefficient against DUEC in China and Singapore. In addition, a thorough discussion of DUEC etiology has recently been published, stating that DUEC (melanotic) occur more frequently in higher phototypes. ${ }^{3}$ The present study, using a population based in São Paulo, Brazil, did not correlate ethnic background, Fitzpatrick skin type, or skin/hair/eye color with DUEC severity. However, this population comprised a high proportion of individuals with multiple ethnic and racial backgrounds, as well as a very low proportion of subjects who self-identified as Asian or "black/ African". In contrast, $26 \%$ of the subjects indicated they were of "mixed" heritage.

The data demonstrate that along with melanin, blood oxygenation and volume account for at least $13 \%$ of the difference between DUEC and cheek skin. Fractional blood volume in the current study was found to be more de oxygenated and higher under the eye in DUEC than in the corresponding cheek skin. The role of blood stasis has been identified elsewhere. Vershoore et al. reported higher hemoglobin content in DUEC skin compared with normal skin. ${ }^{8}$ Some investigators have suggested that at least some periorbital dark circles can be attributed primarily to postinflammatory hemodynamic congestion, which produces a bruising effect on the lower eyelids. ${ }^{12}$

This facet of DUEC is clinically important, since skin whitening products which are designed to reduce melanin are only modestly effective in these circumstances, while analyses of the periorbital area have revealed a poor correlation between visual improvement and decreased melanin. ${ }^{9,13}$

The spectrophotometric color evaluation terms $\Delta \mathrm{L}^{*}$ and $\Delta \mathrm{E}^{*}$ were the most significant instrumental parameters correlated with visual assessment of DUEC severity. This corresponds to the concept that it is the contrast in darkness between the under-eye area and cheek area that contributes most to the perception or severity rating of DUEC rather than the absolute value of $L^{*}$. However, these color parameters do not have a linear relationship to melanin or hemoglobin, therefore, non-contact hyperspectral imaging was used in this study to assess melanin content, blood 
TABLE 3: Allergy history and DUEC

\begin{tabular}{|c|c|c|c|c|c|c|c|c|}
\hline \multirow[t]{2}{*}{ Disease } & & \multirow[t]{2}{*}{$\mathbf{N}$} & \multicolumn{5}{|c|}{ DUEC severity } & \multirow[t]{2}{*}{ P value } \\
\hline & & & 1 & 2 & 3 & 4 & 5 & \\
\hline \multirow[t]{8}{*}{ Asthma } & Self & 10 & 0 & 2 & 1 & 4 & 3 & \\
\hline & & & & & & & & \\
\hline & Relatives & 42 & 1 & 22 & 10 & 6 & 3 & \\
\hline & & & $2.4 \%$ & $52.4 \%$ & $23.8 \%$ & $14.3 \%$ & $7.1 \%$ & 0.010 \\
\hline & Both & 3 & 0 & 3 & 0 & 0 & 0 & \\
\hline & & & $0 \%$ & $100 \%$ & $0 \%$ & $0 \%$ & $0 \%$ & \\
\hline & Neither & 442 & 21 & 125 & 92 & 112 & 69 & \\
\hline & & & $5 \%$ & $29.6 \%$ & $21.8 \%$ & $26.5 \%$ & $16.4 \%$ & \\
\hline \multirow[t]{8}{*}{ Hay fever } & Self & 85 & 4 & 26 & 17 & 23 & 15 & 0.439 \\
\hline & & & $4.7 \%$ & $30.6 \%$ & $20 \%$ & $27.1 \%$ & $17.6 \%$ & \\
\hline & Relatives & 81 & 4 & 32 & 18 & 17 & 10 & \\
\hline & & & $4.9 \%$ & $39.5 \%$ & $22.2 \%$ & $21 \%$ & $12.3 \%$ & \\
\hline & Both & 32 & 2 & 10 & 8 & 7 & 5 & \\
\hline & & & $6.2 \%$ & $31.2 \%$ & $25 \%$ & $21.9 \%$ & $15.6 \%$ & \\
\hline & Neither & 281 & 12 & 85 & 62 & 74 & 45 & \\
\hline & & & $4.3 \%$ & $30.2 \%$ & $22.1 \%$ & $26.3 \%$ & $16 \%$ & \\
\hline \multirow{8}{*}{ Eczema } & Self & 3 & 0 & 1 & 0 & 1 & 1 & 0.250 \\
\hline & & & $0 \%$ & $33.3 \%$ & $0 \%$ & $33.3 \%$ & $33.3 \%$ & \\
\hline & Relatives & 19 & 0 & 11 & 4 & 3 & 1 & \\
\hline & & & $0 \%$ & $57.9 \%$ & $21.1 \%$ & $15.8 \%$ & $5.3 \%$ & \\
\hline & Both & 1 & 0 & 1 & 0 & 0 & 0 & \\
\hline & & & $0 \%$ & $100 \%$ & $0 \%$ & $0 \%$ & $0 \%$ & \\
\hline & Neither & 453 & 22 & 139 & 99 & 117 & 73 & \\
\hline & & & $4.9 \%$ & $30.7 \%$ & $21.9 \%$ & $25.8 \%$ & $16.1 \%$ & \\
\hline
\end{tabular}

${ }^{* *}$ significant at $\mathrm{p}<0,05$

volume, oxygen saturation and dermal scattering.

This measurement system for assessing DUEC provides two main advantages. First, the contribution of each underlying biological factor can be an important indicator of the best treatment target. Second, the data generated from these systems can also be used to measure and authenticate treatment success.

Importantly, this study also showed that visual assessment using a set of graded photographs was well-correlated with the degree of contrast between undereye and cheek lightness values.

Family history was the most significant risk factor for DUEC, whereas Fitzpatrick skin type was not correlated with the risk or severity of DUEC. Virtually all subjects reported that their DUEC was not transient but fixed, and that once the condition was manifest, it did not vary. The average age at which subjects reported first noticing DUEC was 24 years, and a 
TAble 4: Effect of Sleep Quality on DUEC

\begin{tabular}{|c|c|c|c|c|c|c|c|c|}
\hline \multirow[t]{2}{*}{ Attribute } & & \multirow[t]{2}{*}{$\mathbf{N}$} & \multicolumn{5}{|c|}{ DUEC severity } & \multirow[t]{2}{*}{ P value } \\
\hline & & & 1 & 2 & 3 & 4 & 5 & \\
\hline \multirow[t]{4}{*}{ Overall sleep quality } & Very good & 201 & $\begin{array}{l}10 \\
5 \%\end{array}$ & $\begin{array}{l}71 \\
35.3 \%\end{array}$ & $\begin{array}{l}42 \\
20.9 \%\end{array}$ & $\begin{array}{l}46 \\
22.9 \%\end{array}$ & $\begin{array}{l}32 \\
15.9 \%\end{array}$ & 0.537 \\
\hline & Fairly good & 171 & $\begin{array}{l}6 \\
3.5 \%\end{array}$ & $\begin{array}{l}53 \\
31 \%\end{array}$ & $\begin{array}{l}38 \\
22.2 \%\end{array}$ & $\begin{array}{l}46 \\
26.9 \%\end{array}$ & $\begin{array}{l}25 \\
14.6 \%\end{array}$ & \\
\hline & Fairly bad & 66 & $\begin{array}{l}3 \\
4.5 \%\end{array}$ & $\begin{array}{l}22 \\
33.3 \%\end{array}$ & $\begin{array}{l}11 \\
16.7 \%\end{array}$ & $\begin{array}{l}19 \\
28.8 \%\end{array}$ & $\begin{array}{l}11 \\
16.7 \%\end{array}$ & \\
\hline & Bad & 16 & $\begin{array}{l}0 \\
0 \%\end{array}$ & $\begin{array}{l}3 \\
18.8 \%\end{array}$ & $\begin{array}{l}6 \\
37.5 \%\end{array}$ & $\begin{array}{l}3 \\
18.8 \%\end{array}$ & $\begin{array}{l}4 \\
25 \%\end{array}$ & \\
\hline \multirow[t]{4}{*}{ Hours of sleep } & Less than 6 & 59 & $\begin{array}{l}4 \\
6.8 \%\end{array}$ & $\begin{array}{l}18 \\
30.5 \%\end{array}$ & $\begin{array}{l}8 \\
13.6 \%\end{array}$ & $\begin{array}{l}18 \\
30.5 \%\end{array}$ & $\begin{array}{l}10 \\
16.9 \%\end{array}$ & 0.889 \\
\hline & $6-7 \mathrm{~h}$ & 231 & $\begin{array}{l}13 \\
5.6 \%\end{array}$ & $\begin{array}{l}72 \\
31.2 \%\end{array}$ & $\begin{array}{l}54 \\
23.4 \%\end{array}$ & $\begin{array}{l}53 \\
22.9 \%\end{array}$ & $\begin{array}{l}39 \\
169 \%\end{array}$ & \\
\hline & $8-9 \mathrm{~h}$ & 156 & $\begin{array}{l}3 \\
1.9 \%\end{array}$ & $\begin{array}{l}55 \\
35.3 \%\end{array}$ & $\begin{array}{l}33 \\
21.2 \%\end{array}$ & $\begin{array}{l}42 \\
26.9 \%\end{array}$ & $\begin{array}{l}21 \\
13.5 \%\end{array}$ & \\
\hline & More than 9 & 9 & $\begin{array}{l}0 \\
0 \%\end{array}$ & $\begin{array}{l}3 \\
33.3 \%\end{array}$ & $\begin{array}{l}1 \\
11.1 \%\end{array}$ & $\begin{array}{l}3 \\
33.3 \%\end{array}$ & $\begin{array}{l}2 \\
22.2 \%\end{array}$ & \\
\hline \multirow[t]{2}{*}{ Difficulty falling asleep } & Yes & 87 & $\begin{array}{l}3 \\
3.4 \%\end{array}$ & $\begin{array}{l}30 \\
34.5 \%\end{array}$ & $\begin{array}{l}18 \\
20.7 \%\end{array}$ & $\begin{array}{l}21 \\
24.1 \%\end{array}$ & $\begin{array}{l}15 \\
17.2 \%\end{array}$ & 0.937 \\
\hline & No & 363 & $\begin{array}{l}16 \\
4.4 \%\end{array}$ & $\begin{array}{l}117 \\
32.2 \%\end{array}$ & $\begin{array}{l}78 \\
21.5 \%\end{array}$ & $\begin{array}{l}93 \\
25.6 \%\end{array}$ & $\begin{array}{l}56 \\
15.4 \%\end{array}$ & \\
\hline \multirow[t]{2}{*}{ Difficulty staying asleep } & Yes & 84 & $\begin{array}{l}4 \\
4.8 \%\end{array}$ & $\begin{array}{l}22 \\
26.2 \%\end{array}$ & $\begin{array}{l}17 \\
20.2 \%\end{array}$ & $\begin{array}{l}25 \\
29.8 \%\end{array}$ & $\begin{array}{l}16 \\
19 \%\end{array}$ & 0.148 \\
\hline & No & 342 & $\begin{array}{l}16 \\
4.7 \%\end{array}$ & $\begin{array}{l}116 \\
33.9 \%\end{array}$ & $\begin{array}{l}73 \\
21.3 \%\end{array}$ & $\begin{array}{l}80 \\
23.4 \%\end{array}$ & $\begin{array}{l}54 \\
15.8 \%\end{array}$ & \\
\hline \multirow[t]{2}{*}{$\begin{array}{l}\text { Medication for } \\
\text { sleeping problems }\end{array}$} & Yes & 17 & $\begin{array}{l}0 \\
0 \%\end{array}$ & $\begin{array}{l}6 \\
35.3 \%\end{array}$ & $\begin{array}{l}2 \\
11.8 \%\end{array}$ & $\begin{array}{l}6 \\
35.3 \%\end{array}$ & $\begin{array}{l}3 \\
17.6 \%\end{array}$ & 0.567 \\
\hline & No & 214 & $\begin{array}{l}8 \\
3.7 \%\end{array}$ & $\begin{array}{l}69 \\
32.2 \%\end{array}$ & $\begin{array}{l}44 \\
20.6 \%\end{array}$ & $\begin{array}{l}58 \\
27.1 \%\end{array}$ & $\begin{array}{l}32 \\
15 \%\end{array}$ & \\
\hline \multirow[t]{2}{*}{ Tiredness in the morning } & Yes & 210 & $\begin{array}{l}13 \\
6.2 \%\end{array}$ & $\begin{array}{l}68 \\
32.4 \%\end{array}$ & $\begin{array}{l}47 \\
22.4 \%\end{array}$ & $\begin{array}{l}53 \\
25.2 \%\end{array}$ & $\begin{array}{l}28 \\
13.3 \%\end{array}$ & 0.155 \\
\hline & No & 238 & $\begin{array}{l}7 \\
2.9 \%\end{array}$ & $\begin{array}{l}78 \\
32.8 \%\end{array}$ & $\begin{array}{l}46 \\
19.3 \%\end{array}$ & $\begin{array}{l}61 \\
25.6 \%\end{array}$ & $\begin{array}{l}44 \\
18.5 \%\end{array}$ & \\
\hline \multirow[t]{2}{*}{ Sleepiness in the evening } & Yes & 165 & $\begin{array}{l}7 \\
4.2 \%\end{array}$ & $\begin{array}{l}54 \\
32.7 \%\end{array}$ & $\begin{array}{l}42 \\
25.5 \%\end{array}$ & $\begin{array}{l}45 \\
27.3 \%\end{array}$ & $\begin{array}{l}16 \\
9.7 \%\end{array}$ & 0.245 \\
\hline & No & 282 & $\begin{array}{l}13 \\
4.6 \%\end{array}$ & $\begin{array}{l}94 \\
33.3 \%\end{array}$ & $\begin{array}{l}50 \\
17.7 \%\end{array}$ & $\begin{array}{l}69 \\
24.5 \%\end{array}$ & $\begin{array}{l}54 \\
19.1 \%\end{array}$ & \\
\hline \multirow[t]{2}{*}{ Sleepiness during the day } & Yes & 148 & $\begin{array}{l}7 \\
4.7 \%\end{array}$ & $\begin{array}{l}42 \\
28.4 \%\end{array}$ & $\begin{array}{l}34 \\
23 \%\end{array}$ & $\begin{array}{l}43 \\
29.1 \%\end{array}$ & $\begin{array}{l}21 \\
14.2 \%\end{array}$ & 0.434 \\
\hline & No & 300 & $\begin{array}{l}13 \\
4.3 \%\end{array}$ & $\begin{array}{l}107 \\
35.7 \%\end{array}$ & $\begin{array}{l}59 \\
19.7 \%\end{array}$ & $\begin{array}{l}70 \\
23.3 \%\end{array}$ & $\begin{array}{l}49 \\
16.3\end{array}$ & \\
\hline
\end{tabular}




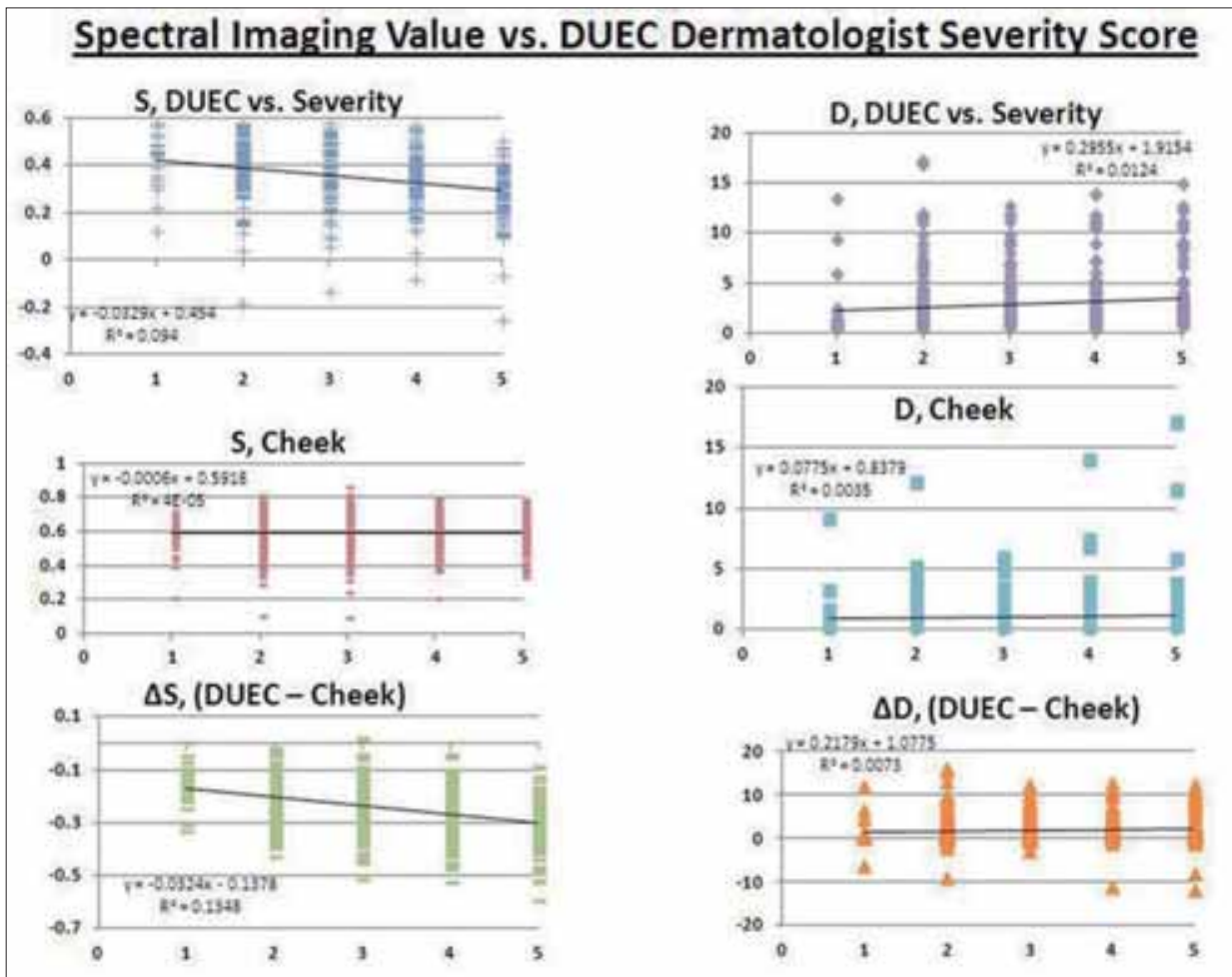

\section{Spectral Imaging Value vs. DUEC Dermatologist Severity Score}
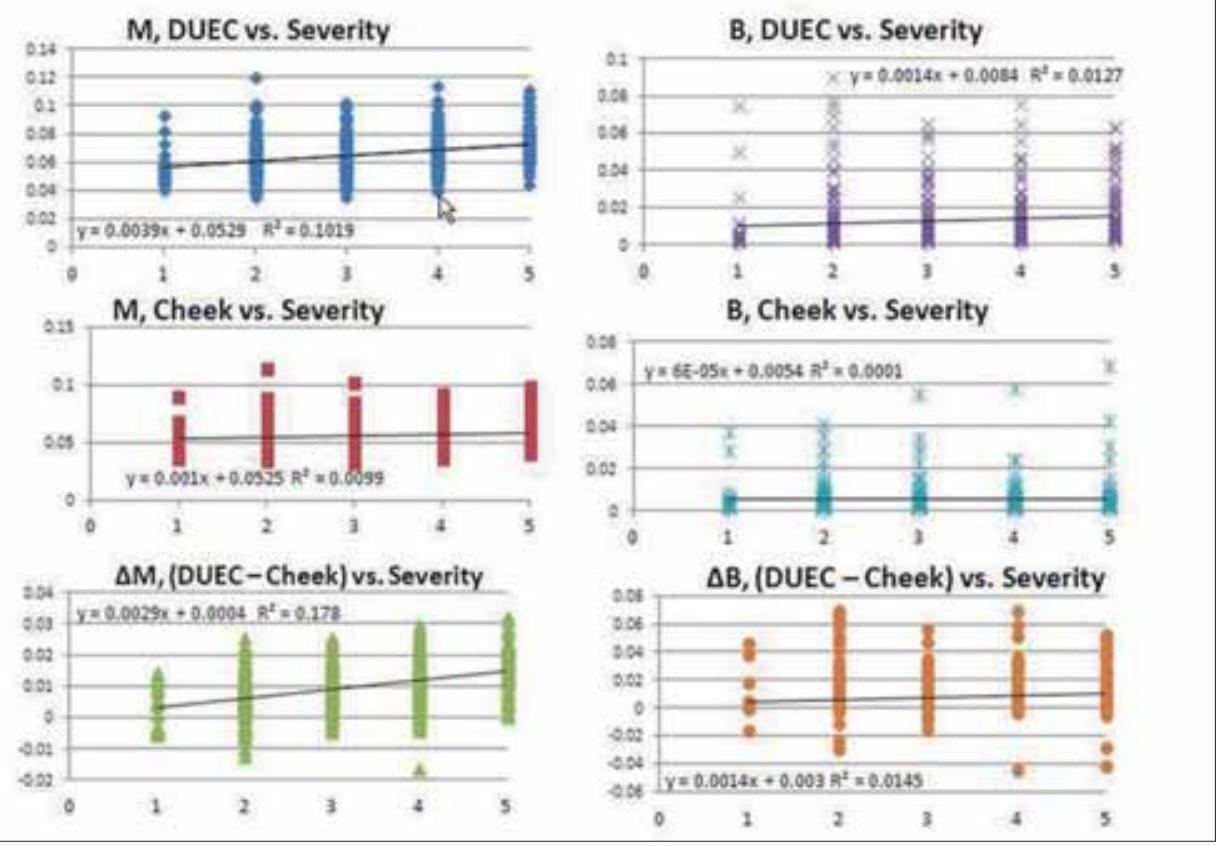

Figure 2: A-D Spectral imaging values for melanin, oxygenated blood, and dermal scattering taken from under the eye and from the cheek. $\mathrm{M}=$ melanin, $\mathrm{B}=$ blood volume, $\mathrm{S}=$ hemoglobin oxygen saturation and $\mathrm{D}=$ dermal scattering factor. The within-subject difference between readings for the under-eye area and the cheek area is indicated by $\Delta$. The volume fraction amounts of melanin $(\mathrm{M})$, the average volume fraction of whole blood $(150 \mathrm{~g} \mathrm{Hb} /$ liter) (B), the oxygen saturation of the blood (S) and the dermal scattering coefficient (D) were evaluated

younger onset correlated with higher severity scores. Although Vershoore et al. did not find any association with family history in their study of 33 subjects, others have reported strong evidence of inheritance. , $^{8,11}$

Asthma was significantly associated with DUEC scores, but self-reported allergy was not. It should be noted that subjects were not asked about a medical diagnosis of allergy. Although they were not asked directly about a diagnosis of atopic dermatitis, it can be hypothesized that those who identified themselves and/or family members as having asthma may also have a history of atopy. Family history of 
DUEC may be related to family history of atopy, a condition known to result in peri-ocular inflammation and blood stasis. Certainly, the "allergic shiner" is a diagnostic feature of atopy, and in this study, blood volume under the eye was positively associated with DUEC severity. The possible relationship with atopy would also be congruent with the data showing that both melanin and deoxygenated blood volume (if melanin was deposited due to chronic inflammation) are the most important factors in DUEC severity.

The present findings that family history and asthma are risk factors linked to DUEC contradict other studies. For example, Verschoore et al. reported that in their 33 patients, no significant correlation existed between DUEC prevalence and family history, atopic or contact dermatitis, contemporaneous melasma or hormonal factors. ${ }^{8}$ They did argue, however, that melanin deposits and blood stasis in dark circles may play a role in the pathogenesis of DUEC. The current study is in agreement with another report that used a large number of subjects. Furthermore, the authors of the latter study concluded that there was a significant correlation between DUEC and family history, as well as a personal history of eczema, asthma atopy and allergic rhinitis. ${ }^{11}$ Other authors have also stated that there appears to be a genetic basis for DUEC. ${ }^{9}$

One of the most interesting findings from this study was that sleep quantity and quality were not correlated with physician-assessed DUEC severity. It is often reported that DUEC are either caused or worsened transiently by sleep deprivation, but this is usually the opinion given by subjects when asked about the cause of their DUEC. ${ }^{1}$ Further, there is a cultural bias in many regions that strongly associates DUEC with exhaustion or sickness. For example, the Japanese language has several words descrivbing
DUEC, which can also denote looking exhausted or the absence of lightness (presence of darkness), as well as suggesting that DUEC are a sign of aging.

However, in at least one other study, although $41.5-51 \%$ of patients reported that sleep deprivation and insomnia aggravated their DUEC, there was no statistically significant correlation between sleep deprivation and DUEC. ${ }^{11}$ Moreover, the study did not detect effects from smoking or alcohol intake. A recent study by Axelsson et al. showed that individuals subjected to acute sleep deprivation (31 hours after short sleep) were more likely to be rated as tired looking, less healthy and less attractive than after a full night's sleep. ${ }^{14}$ However, the study did not evaluate DUEC.

In conclusion, DUEC is a common, aesthetic complaint that can decrease quality of life. Although typically associated with lack of sleep (at least by the lay public), this study demonstrates that DUEC is more likely to be familial in origin and unlikely to be caused by sleep deprivation. The main factors contributing to the appearance of DUEC as assessed by hyperspectral imaging analysis are melanin and (deoxygenated) blood, although the effect of eyearea geometry (shadowing) cannot be ruled out. Despite the differences in dermal scattering between the eye and cheek, they appeared not to contribute significantly to DUEC severity. This contrasts with one report explaining that dermal thickness was lower in subjects with DUEC than in subjects without DUEC. ${ }^{7}$ To our knowledge, this is the first comprehensive study that examines the relationship between a standardized visual assessment of DUEC severity and an instrumental evaluation of color and markers for biological contributors such as melanin, blood volume, blood oxygen saturation, and dermal scattering. 


\section{REFERENCES}

1. Freitag FM, Cestari TF. What causes dark circles under the eyes? J Cosmet Dermatol. 2007;6:211-5.

2. Roh MR, Chung KY: Infraorbital dark circles: definition, causes, and treatment options. Dermatol Surg. 2009;35:1163-71.

3. Souza DM, Ludtke C, Souza ER, Scandura KMP and Weber MB: Periorbital hyperchromia. Surg Cosmet Dermatol. 2011;3:233-239.

4. Yaar M, Gilchrest BA: Skin aging: postulated mechanisms and consequent changes in structure and function. Clin Geriatr Med. 2001;17:617-30, v.

5. Momosawa A, Kurita M, Ozaki M, Miyamoto S, Kobayashi Y, Ban I, et al. Combined therapy using Q-switched ruby laser and bleaching treatment with tretinoin and hydroquinone for periorbital skin hyperpigmentation in Asians. Plast Reconstr Surg. 2008;121:282-8.

6. Jacques S, Samatham R, and Choudhury, N: Rapid spectral analysis for spectral imaging, Biomed Opt Express. 2010;1:157-164

7. Ohshima H, Takiwaki H. Evaluation of dark circles of the lower eyelid: comparison between reflectance meters and image processing and involvement of dermal thickness in appearance. Skin Res Technol. 2008;14:135-41.

8. Verschoore M, Gupta S, Sharma VK, Ortonne JP. Determination of Melanin and Haemoglobin in the Skin of Idiopathic Cutaneous Hyperchromia of the Orbital region (ICHOR): A Study of Indian Patients. J Cutan Aesthet Surg. 2012;5:176-82.

9. Watanabe S, Nakai K, Ohnishi T. Condition known as "dark rings under the eyes" in the Japanese population is a kind of dermal melanocytosis which can be successfully treated by Q-switched ruby laser. Dermatol Surg. 2006;32:785-9.

10. Graziosi AC, Quaresma MR, Michalany NS, Ferreira LM. Cutaneous Idiopathic Hyperchromia of the Orbital Region (ClHOR): A Histopathological Study. Aesthetic Plast Surg. 2013;37:434-8.
11. Ranu H, Thng S, Goh BK, Burger A, Goh CL. Periorbital hyperpigmentation in Asians: an epidemiologic study and a proposed classification. Dermatol Surg. 2011;37:1297-303.

12. Eberlin S, Del Carmen Velazquez Pereda M, de Campos Dieamant G, Nogueira C, Werka RM, de Souza Queiroz ML. Effects of a Brazilian herbal compound as a cosmetic eyecare for periorbital hyperchromia ("dark circles"). J Cosmet Dermatol. 2009;8:127-35.

13. West TB, Alster TS. Improvement of infraorbital hyperpigmentation following carbon dioxide laser resurfacing. Dermatol Surg. 1998;24:615-6.

14. Axelsson J, Sundelin T, Ingre M, Van Someren EJ, Olsson A, Lekander M. Beauty sleep: experimental study on the perceived health and attractiveness of sleep deprived people. BMJ. 2010 Dec 14;341:c6614.

M AILING ADDRESS:

Sérgio Schalka

Rua A tílio D elanina, 178 -V ila Campesina

06023-070 - O sasco - SP

E-mail: sergio@medcinonline.com.br

How to cite this article: Matsui MS, Schalka S, Vanderover G, Fthenakis CG, Ennis CJ, Bombarda PCP, Bueno JR, Viscomi BLI, Bombarda Jr MS. Physiological and lifestyle factors contributing to risk and severity of peri-orbital dark circles in a Brazilian population. An Bras Dermatol. 2015;90(4):494-503. 